\title{
PRINSIP PENULISAN BAHAN AJAR BAHASA MANDARIN YANG EFEKTIF UNTUK JURUSAN KOMUNIKASI PEMASARAN UNIVERSITAS BINA NUSANTARA
}

\author{
Kelly Rosalin; Agustian \\ Chinese Department, Faculty of Humanities, Bina Nusantara University \\ Jln. Kemanggisan Ilir III, No. 45, Kemanggisan - Palmerah, Jakarta Barat 11480 \\ krosalin@binus.edu; agustian@binus.edu
}

\begin{abstract}
Article discussed the writing principles that must be considered in compiling Chinese language teaching material specifically used for Marketing Communication students regarding the interest and target of Marketing Communication of Bina Nusantara University. The methodologies used are descriptive quantitative for distributing questionnaires and qualitative approach through observation and interview. Research found the appropriate and effective Chinese language teaching material would enhance the standard of Chinese language learning. At present, Chinese language teaching material used by Marketing Communication students has not been able to fulfill their requirements. In addition, the target learners of the teaching material are universal.
\end{abstract}

Keywords: teaching material, Marketing Communication, Chinese language

\begin{abstract}
ABSTRAK
Penelitian membahas tentang prinsip-prinsip penulisan yang harus diperhatikan dalam penyusunan bahan ajar bahasa Mandarin. Bahan ajar yang disusun khusus digunakan untuk mahasiswa/i jurusan Komunikasi Pemasaran dengan memerhatikan kepentingan dan target program studi Komunikasi Pemasaran Universitas Bina Nusantara. Metodologi yang digunakan dalam penelitian ini adalah kuantitatif deskriptif untuk penyebaran kuesioner dan pendekatan kualitatif melalui observasi dan wawancara. Penelitian menemukan bahwa bahan ajar bahasa Mandarin yang sesuai dan efektif dapat meningkatkan standar pembelajaran bahasa Mandarin. Hal ini disebabkan bahan ajar bahasa Mandarin yang digunakan sekarang masih belum dapat memenuhi kebutuhan mereka. Ditambah lagi, bahan ajar bahasa Mandarin yang digunakan masih bersifat umum.
\end{abstract}

Kata kunci: bahan ajar, jurusan Komunikasi Pemasaran, bahasa Mandarin 


\section{PENDAHULUAN}

Perekonomian China kini menduduki peringkat ke-2 terbesar di dunia, di bawah Amerika Serikat. China berhasil menggeser Jepang yang sudah 40 tahun menjadi negara dengan perekonomian terbesar ke-2 di dunia (Qomariyah, 2011). Economy Watch meramalkan bahwa pada 2035, China diprediksi mampu menggeser AS sebagai negara dengan ekonomi terbesar nomor 1 di dunia. Pertumbuhan ekonomi China yang begitu pesat membuat jumlah orang yang ingin belajar bahasa Mandarin makin banyak (Economy Watch, 2010).

Data dari Forum Internasional Bahasa Mandarin di Shanghai menyebutkan bahwa kini ada lebih dari 2.027 universitas dari 85 negara di seluruh dunia yang menawarkan kursus bahasa Mandarin. Peningkatan penawaran ini terutama dipicu oleh keberhasilan China dalam mengajukan diri sebagai tuan rumah Olimpiade dan keberhasilan dalam masuknya China menjadi anggota WTO. Data statistik dari forum yang sama juga menyebutkan bahwa ada sekitar 25 juta orang yang berminat mempelajari bahasa Mandarin. (Tanaga, 2008)

Di Indonesia sekarang sudah ada beberapa universitas yang membuka jurusan Sastra China dan juga terdapat banyak lembaga kursus bahasa Mandarin. Di Universitas Bina Nusantara bahasa Mandarin tidak hanya dipelajari oleh mahasiswa/i jurusan Sastra China, tetapi juga oleh beberapa jurusan di luar Sastra China yang mewajibkan mahasiswa/i untuk mengambil program bahasa Mandarin, seperti jurusan Komunikasi Pemasaran, Hotel Management, Manajemen, Hubungan Internasional, dan juga Komputer Akuntansi.

Penelitian ini mengambil jurusan Komunikasi Pemasaran sebagai objek penelitian karena jurusan ini mewajibkan mahasiswa/inya untuk mempelajari bahasa Mandarin selama 4 semester. Selain itu, dibandingkan jurusan lain, program bahasa Mandarin jurusan Komunikasi Pemasaran banyak sekali mendapatkan tanggapan positif maupun negatif dari mahasiswa dan dosen. Melalui pengalaman langsung dari peneliti, ditemukan bahwa bahan ajar bahasa Mandarin yang dipakai oleh mahasiswa/i jurusan Komunikasi Pemasaran masih kurang sesuai kebutuhan mereka dan juga masih menggunakan bahan ajar bahasa Mandarin terbitan China. Di sisi lain, minat mahasiswa/i terhadap pembelajaran bahasa Mandarin masih sangat kurang.

Prastowo (2011) menyebutkan bahwa dengan adanya dinamika dan perkembangan dalam dunia pendidikan, pendidik dituntut untuk lebih kreatif dalam melakukan berbagai inovasi pembelajaran. Salah satunya adalah inovasi perlu dilakukan terhadap bahan ajar. Oleh karena itu, penelitian ini diharapkan dapat menemukan prinsip-prinsip yang harus diperhatikan dalam penulisan bahan ajar bahasa Mandarin untuk meningkatkan minat mahasiswa/i jurusan Komunikasi Pemasaran.

\section{METODE}

Metode penelitian yang dipakai dalam penelitian ini adalah metode penelitian gabungan antara metode kualitatif dan kuantitatif. Pendekatan kuantitatif dipakai untuk mengetahui minat mahasiswa/i jurusan Komunikasi Pemasaran terhadap materi yang dipelajari. Sementara pendekatan kualitatif dipakai untuk mengetahui sasaran dan tujuan dari program studi Komunikasi Pemasaran setelah mahasiswa/i mempelajari bahasa Mandarin.

Teknik pengumpulan data dilakukan dengan membagikan kuesioner untuk mahasiswa/i tahun pertama jurusan Komunikasi Pemasaran Universitas Bina Nusantara. Kuesioner diberikan kepada mereka yang sudah mendapatkan pelajaran bahasa Mandarin I dan II pada semester 1 dan 2 di kampus Anggrek dan kampus Alam Sutera. Selain melalui kuesioner, wawancara dilakukan terhadap Ketua Jurusan Komunikasi Pemasaran untuk memperkuat analisis data.

\section{HASIL DAN PEMBAHASAN}

\section{Kebutuhan Bahasa Mandarin Jurusan Komunikasi Pemasaran}

Universitas Bina Nusantara merupakan universitas pertama yang mewajibkan mahasiswa/i jurusan Komunikasi semester 1 dan 2 untuk mengambil mata kuliah bahasa Mandarin sebagai mata kuliah wajib dengan bobot 4 SKS dan lulus dengan minimal nilai C. Dapat dilihat bahwa betapa penting mata kuliah bahasa Mandarin bagi mahasiswa/i jurusan Komunikasi Pemasaran Universitas Bina Nusantara. Ini juga merupakan salah satu daya tarik yang membuat jurusan Komunikasi Pemasaran Universitas Bina Nusantara berbeda dengan universitas lainnya yang memiliki jurusan Komunikasi Pemasaran.

Jurusan Komunikasi Pemasaran memilih mata kuliah bahasa Mandarin sebagai mata kuliah wajib untuk mendukung visi dan misi Universitas Bina Nusantara menuju World Class University, sehingga setiap jurusan wajib mempersiapkan lulusannya untuk bekerja di perusahaan global. Seiring dengan pertumbuhan ekonomi Tiongkok yang sangat pesat, banyak sekali perusahaan Tiongkok yang melakukan investasi di Indonesia, sehingga terlihat bahwa lulusan yang memiliki kemampuan berbahasa Mandarin akan mendapatkan peluang yang sangat besar untuk bekerja di perusahaan global. Selain itu, banyak sekali kebutuhan dari luar seperti permintaan dari kalangan industri yang membutuhkan mahasiswa/i jurusan Komunikasi Pemasaran yang fasih berbahasa Mandarin untuk magang maupun bekerja di tempat mereka.

Meskipun demikian, hanya sebagian kecil mahasiswa/i jurusan Komunikasi Pemasaran yang sudah menguasai bahasa Mandarin sebagai bahasa ibu, seperti mahasiswa/i yang berasal dari Bangka, Riau, Pontianak, Medan, dan lain-lain. Bahkan, di antara mereka sudah ada yang menjadi penerjemah. Berdasarkan hasil kuesioner, dari 185 mahasiswa/i sebelum mengambil jurusan Komunikasi Pemasaran Universitas Bina Nusantara, terdapat 95 mahasiswa/i yang sama sekali tidak mempunyai dasar bahasa Mandarin. Sedangkan 90 mahasiswa/i lainnya sudah mempunyai dasar bahasa Mandarin dengan rata-rata waktu belajar adalah 5 tahun 4 bulan. Dari 90 mahasiswa/i ini terdapat 14 mahasiswa/i yang sudah mempelajari bahasa Mandarin lebih dari 11 tahun. Dengan demikian latar belakang penguasaan bahasa Mandarin setiap mahasiswa berbeda-beda, sehingga menyebabkan adanya jarak antara mahasiswa/i yang mempunyai dasar bahasa Mandarin dengan yang tidak mempunyai dasar sama sekali. 
Sementara itu, ada sebagian dari mereka yang tidak mempunyai ketertarikan terhadap bahasa Mandarin. Berdasarkan hasil kuesioner, dari 185 mahasiswa/i terdapat 99 mahasiswa/i yang menyukai bahasa Mandarin dengan alasan yang paling umum karena ingin mempelajari bahasa asing selain bahasa Inggris, menambah wawasan, dan bermanfaat. Sedangkan 83 mahasiswa/i lainnya tidak menyukai pelajaran bahasa Mandarin dengan alasan utama menurut mereka bahasa Mandarin terlalu susah untuk dipelajari terutama bagian karakter China (Hanzi). Ini juga menjadi salah satu alasan utama mereka tidak menyukai bahasa Mandarin. Berdasarkan hal tersebut, jurusan Komunikasi Pemasaran ingin mahasiwa/i yang tidak mempunyai dasar dan tidak begitu tertarik dengan bahasa Mandarin juga dapat menguasai bahasa Mandarin setelah mengambil mata kuliah ini.

Harapan dari jurusan Komunikasi Pemasaran adalah agar bahasa Mandarin yang dipelajari oleh mahasiswa/i Komunikasi Pemasaran lebih mengutamakan berbicara dan membaca serta sesuai dengan dunia profesi mereka. Dengan begitu mereka dapat bekerja dengan perusahaan yang menggunakan bahasa Mandarin, yang dalam jurusan Komunikasi Pemasaran terdapat 4 jenis peminatan, seperti Digital Journalism, Broadcasting, Marketing Public Relation, dan Cooperate Public Relation. Diharapkan, dalam mata kuliah bahasa Mandarin mereka diberikan materi tentang pengenalan dunia profesi yang sesuai dengan peminatan yang dipilih oleh mahasiswa/i tersebut dalam bahasa Mandarin, sehingga ketika mereka mendengar istilah-istilah yang terkait dalam bahasa Mandarin, mereka tidak akan merasa asing. Misalnya untuk bidang peminatan Digital Journalism, mahasiswa/i dapat mengerti kosakata yang berhubungan dengan wartawan, narasumber dalam bahasa Mandarin. Untuk bidang peminatan Broadcasting, diharapkan mahasiswa/i dapat dibawa ke dunia kerja, seperti menjadi presenter, penulis naskah, rumah produksi, dan lain-lain. Untuk bidang peminatan Marketing Public Relation, diharapkan mahasiswa/i diberikan pengetahuan maupun pengenalan yang berhubungan dengan event, branding serta cara berinteraksi, negosiasi dalam bahasa Mandarin. Sedangkan untuk peminatan Cooperate Public Relation diberikan pengetahuan maupun pengenalan terhadap bagian-bagian yang ada dalam perusahaan, seperti posisi, image perusahaan, serta reputasi perusahaan dalam bahasa Mandarin. Dengan demikian, mahasiswa/i jurusan Komunikasi Pemasaran akan terbantu. Ketika memasuki dunia global, mereka mempunyai nilai tambah dan lebih mudah beradaptasi dengan lingkungan kerja karena mereka sudah dibekali dengan pengetahuan dan pengenalan bidang mereka dalam bahasa Mandarin.

Mahasiswa/i jurusan Komunikasi Pemasaran memiliki berbagai ekspektasi setelah mengambil mata kuliah bahasa Mandarin I dan II di Universitas Bina Nusantara. Berdasarkan jawaban kuesioner terdapat 142 mahasiswa/i yang berharap mereka dapat menguasai bahasa Mandarin dasar, meningkatkan kemampuan bahasa Mandarin mereka, fasih berbicara bahasa asing seperti bahasa Mandarin selain bahasa Inggris. Selain itu, mahasiswa/i juga berharap bahasa Mandarin yang mereka pelajari dapat digunakan dalam kehidupan sehari-hari mereka maupun dalam dunia kerja sehingga menjadi nilai tambah ketika mereka melamar kerja.

\section{Bahan Ajar}

Bahan ajar bahasa Mandarin yang dipakai jurusan Komunikasi Pemasaran adalah buku Hanyu Changcheng (Great Wall Chinese) volume 1 dan 2 (Hanban, 2006), untuk mata kuliah Bahasa Mandarin I yang digunakan mahasiswa/i semester 1. Sedangkan untuk mata kuliah Bahasa Mandarin II menggunakan buku Hanyu Changcheng (Great Wall Chinese) volume 3 dan 4 (Hanban, 2006).

Bahan ajar bahasa Mandarin Hanyu Changcheng (Great Wall Chinese) merupakan proyek utama yang direncanakan dan diorganisasi oleh China National Office for teaching Chinese as a Foreign Language (NOCFL), yang menggunakan perkembangan teknologi multimedia sebagai cara pengajaran yang baru. Tujuan utama dibuatnya bahan ajar ini adalah membina kemampuan pembelajar untuk berkomunikasi dengan menggunakan bahasa Mandarin, menggunakan berbagai metode pengajaran seperti multimedia, CD, F2F, buku teks, dan buku latihan untuk memenuhi permintaan pembelajar bahasa Mandarin bagi orang asing baik di Tiongkok maupun di luar Tiongkok yang tidak dibatasi oleh waktu, tempat maupun kemampuan berbahasa Mandarin.

Setiap volume dari bahan ajar Hanyu Changcheng (Great Wall Chinese) terdiri dari dua buku, yaitu buku teks dan buku latihan. Setiap volume memiliki 10 topik dan cerita dalam buku teks Hanyu Changcheng berkaitan dengan bisnis, cinta, legenda, dan kontemporer. Sedangkan topik-topik yang ada dalam buku teks berkaitan dengan ekonomi, budaya, olahraga, etika, dan lain-lain. Teks secara terorganisasi menggabungkan alur cerita dengan pembelajaran bahasa, bahasa yang digunakan nyata, alami, asli, dan praktis.

Bahan ajar Hanyu Changcheng (Great Wall Chinese) volume 1 sampai 4 diperuntukkan pembelajar bahasa Mandarin dasar. Isi buku-buku ini berkaitan dengan informasi pribadi, kemampuan berkomunikasi, kehidupan sehari-hari, belajar, bekerja, serta kegiatan dalam masyarakat. Tujuannya adalah mengatasi masalah komunikasi menggunakan bahasa Mandarin dalam kehidupan sehari-hari.

Buku teks Hanyu Changcheng (Great Wall Chinese) terdiri dari 5 bagian, yaitu bagian pengenalan karakter utama dalam percakapan, tabel jenis kata, daftar isi, unit, glosarium. Setiap unit dalam bahan ajar Hanyu Changcheng (Great Wall Chinese) terdapat 2 bagian yaitu kosakata dan 3 buah dialog. Tabel 1 merupakan contoh kosakata dalam bahan ajar Hanyu Changcheng (Great Wall Chinese). Sedangkan Gambar 1 merupakan contoh dialog dalam bahan ajar Hanyu Changcheng (Great Wall Chinese).

Tabel 1 Daftar Kosakata Bahan Ajar Hanyu Changcheng (Great Wall Chinese)

\begin{tabular}{ccccc}
\hline 1 & 在 & zài & 介 & at, in, on \\
2 & 家 & jiā & 量 & Measure word \\
3 & 公司 & gōngsī & 名 & Firm, company \\
4 & 工作 & gōngzuò & 名 & To work \\
5 & 大家 & dàjiā & 代 & everybody \\
\hline
\end{tabular}




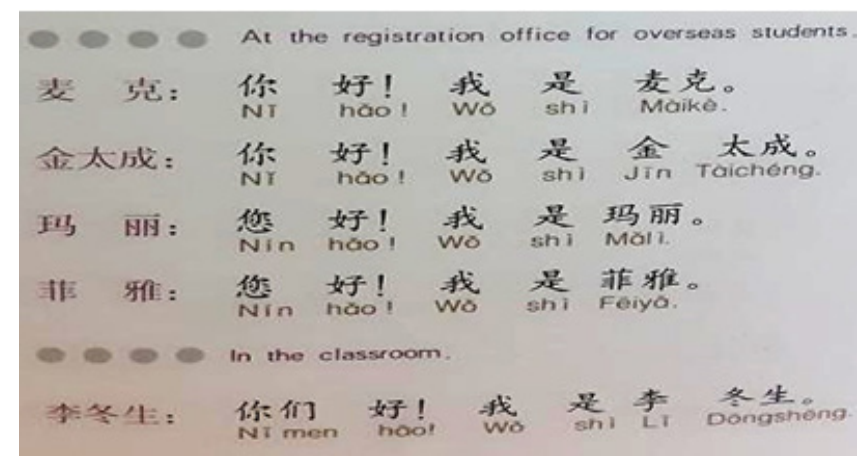

Gambar 1 Dialog Unit 1 Lesson 2

Tidak semua materi yang terdapat dalam bahan ajar ini digunakan sebagai materi untuk mata kuliah Bahasa Mandarin I dan Bahasa Mandarin II jurusan Komunikasi Pemasaran. Tabel 2 menunjukkan topik-topik yang dipelajari oleh mahasiswa/i jurusan Komunikasi Pemasaran untuk bahasa Mandarin I.

Tabel 2 Topik Bahasa Mandarin I

\begin{tabular}{ll}
\hline Great Wall Chinese Volume I & Great Wall Chinese Volume II \\
\hline The Basic Chinese Phonetic and & Birthday \\
Tones & \\
Introducing Self & Place \\
Nationality & Buy \\
Job & Telephone \\
Age & Transportation \\
Friends & Asking and offering \\
Address & \\
Family & \\
Time & \\
Introduce Friends & \\
\hline
\end{tabular}

Tabel 3 adalah topik-topik yang dipelajari oleh mahasiswa/i jurusan Komunikasi Pemasaran untuk bahasa Mandarin II.

Tabel 3 Topik Bahasa Mandarin II

\begin{tabular}{ll}
\hline Great Wall Chinese Volume III & Great Wall Chinese Volume IV \\
\hline $\begin{array}{l}\text { The basic Chinese phonetic, } \\
\text { tones, strokes and character }\end{array}$ & Our class \\
Weather & Shopping \\
Habit & Majority and ability \\
How to post a letter & Campus life \\
$\begin{array}{l}\text { The basic Chinese speaking and } \\
\text { writing }\end{array}$ & Future and dream \\
Money, exchange rate, currency & Planning about vacation \\
Sick, Illness & Holiday vacation \\
\hline
\end{tabular}

Prinsip Penulisan Bahan Ajar Bahasa Mandarin Jurusan Komunikasi Pemasaran

Menurut Li (2006), bahan ajar merupakan petunjuk pengajaran bagi pengajar, yang bertujuan untuk membantu pengajar melaksanakan kegiatan mengajar dan bahan ajar juga merupakan pegangan dasar bagi pembelajar untuk belajar, sehingga pembelajar dengan bahan ajar saja dapat belajar autodidak. Dalam melakukan kegiatan pengembangan bahan ajar, beberapa pertimbangan penting yang perlu dipahami mencakup (1) mengidentifikasi tujuan pembelajaran, (2) melakukan analisis pembelajaran, (3) menganalisis peserta didik dan konteks, (4) menulis tujuan instruksional khusus (kompetensi dasar), (5) mengembangkan instrumen asesmen, (6) mengembangkan strategi pembelajaran, (7) mengembangkan dan menyeleksi materi pem- belajaran, (8) mendesain dan melakukan evaluasi formatif, (9) melakukan revisi, dan (10) mendesain dan melakukan evaluasi sumatif (Dick, Carey, \& Carey, 2005).

Kriteria penggunaan bahasa dalam pengembangan bahan ajar, Muslich (2010) menyebutkan kriteria kelayakan bahasa yang baik, antara lain sebagai berikut. Pertama, kesesuaian pemakaian bahasa dengan perkembangan inelektual, sosial, dan emosional siswa. Kedua, pemakaian bahasa yang komunikatif, indikatornya adalah keterbacaan pesan dan ketepatan kaidah kebahasaan. Ketiga, keruntutan dan keterpaduan alur pikir, indikatornya adalah keruntutan dan keterpaduan antarbab serta antarparagraf (Muslich, 2010: 303-305).

Komponen utama di dalam sistematika bahan ajar adalah (1) tinjauan kompetensi, (2) pendahuluan, (3) bagian inti, (4) penutup, (5) daftar pustaka, dan (6) lampiran (Pannen \& Purwanto, 2011). Menurut Xun (2010), bahan ajar yang baik adalah bahan ajar yang isinya berkaitan erat dengan budaya setempat. Dalam penulisan bahan ajar ada beberapa prinsip dasar yang perlu dipatuhi seperti terfokus, bersifat praktikal, bersifat ilmiah, menarik, sistemik.

Oleh karena itu, penulis beranggapan dalam penulisan bahan ajar bahasa Mandarin untuk jurusan Komunikasi Pemasaran harus memerhatikan tiga buah prinsip utama dalam penulisan, yaitu terfokus, bersifat praktikal, dan menarik.

\section{Terfokus}

Bahan ajar pada umumnya sangat peka terhadap kebutuhan siswa, yang sekalipun buku ajar tidak disusun secara khusus bagi siswa, buku ajar bisa membantu siswa dalam efisiensi waktu dan uang; dan buku ajar mampu beradaptasi dan berimprovisasi terhadap kebutuhan siswa (O’Neill, 1982). Bahan ajar adalah sesuatu yang dipelajari oleh siswa, bahan ajar yang tidak mengenal pembelajarnya adalah bahan ajar yang hanya omong kosong, mengenali pembelajar adalah hal yang penting dalam menggunakan bahan ajar (Xiaobing, 2012).

Berdasarkan hasil kuesioner, 168 mahasiswa/i jurusan Komunikasi Pemasaran Universitas Bina Nusantara merasa bahan ajar bahasa Mandarin yang digunakan sekarang dapat membantu mereka belajar bahasa Mandarin. Sedangkan 17 mahasiswa/i sisanya merasa bahan ajar bahasa Mandarin yang mereka gunakan sekarang tidak membantu mereka belajar bahasa Mandarin. 
Akan tetapi, menurut 161 mahasiswa/i, bahan ajar bahasa Mandarin yang digunakan tidak sesuai dengan kebutuhan mereka karena bahan ajar yang digunakan sekarang tidak sesuai dengan tingkat mereka yang masih pemula, terlalu susah dan rumit untuk dipelajari, dan masih kurang berhubungan dengan jurusan Komunikasi Pemasaran.

Sedangkan hasil wawancara dengan ketua jurusan Komunikasi Pemasaran, Ibu Ulani Yunus, menyebutkan bahwa beliau sudah melihat bahan ajar bahasa Mandarin yang digunakan serta sudah melakukan wawancara dengan dosen pengajar dan mahasiswa/i yang sudah mengambil mata kuliah Bahasa Mandarin I dan II. Menurutnya, bahan ajar yang digunakan sekarang, jika untuk tingkat pemula yang belum bisa berbahasa Mandarin, akan membuat mereka stres karena materi yang diberikan terlalu banyak dan tidak dibawa ke dunia mereka. Topik yang ada juga terlalu luas dan umum, kecuali jika mereka ingin dicetak menjadi pembicara dalam bahasa Mandarin; namun dalam jurusan Komunikasi Pemasaran, bahasa Mandarin merupakan salah satu mata kuliah yang mendukung keterampilan berbahasa mahasiswa/i dan bukanlah fokus utama. Bahan ajar yang terlalu mendasar dan meluas akan menghilangkan minat mahasiswa/i yang belum mempunyai dasar bahasa Mandarin.

Dilihat dari topik yang dipelajari untuk mata kuliah Bahasa Mandarin I dan Bahasa Mandarin II, bahan ajar yang dipakai oleh mahasiswa/i jurusan Komunikasi Pemasaran masih kurang sesuai dengan kebutuhan dan permintaan dari jurusan Komunikasi Pemasaran. Berdasarkan hasil kuesioner, dari sejumlah topik yang dipelajari dalam mata kuliah Bahasa Mandarin I, hanya ada 5 topik yang menarik perhatian mereka. Topik introduce self adalah topik dengan jumlah peminat terbanyak sebanyak 113 . Sedangkan topik job; asking and offering; the basic Chinese phonetic and tones; Introduce friends, masing-masing menempati posisi kedua, ketiga, keempat, dan kelima. Selain kelima topik tersebut, topik-topik lain tidak terlalu diminati oleh mahasiswa/i jurusan Komunikasi Pemasaran. Untuk mata kuliah Bahasa Mandarin II, 95 mahasiswa/i memilih topik mengenai The Basic Chinese Speaking and Writing. Sedangkan untuk topik Campus Life; The Basic Chinese Phonetic, Tones, Stroke and Character; Money, Exchange Rate and Currency; Majority and Ability, masing-masing menempati posisi kedua, ketiga, keempat, dan kelima. Gambar 2 dan 3 menunjukkan topik bahasa Mandarin I dan II yang diminati mahasiswa/i.

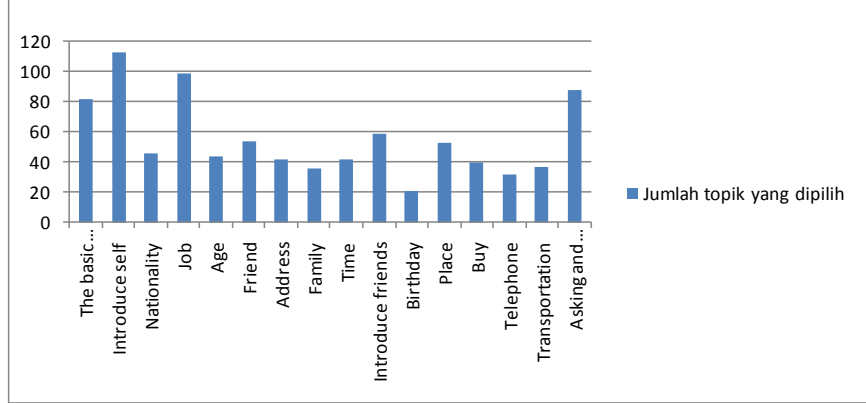

Gambar 2 Topik Bahasa Mandarin I yang Diminati Mahasiswa/i Jurusan Komunikasi Pemasaran

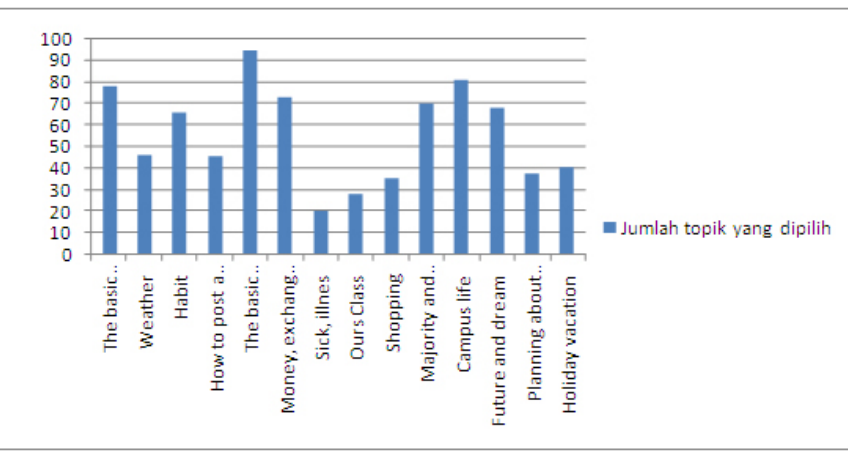

Gambar 3 Topik Bahasa Mandarin II Mahasiswa/i Jurusan Komunikasi Pemasaran

Dari 185 responden, 73 mahasiswa/i jurusan Komunikasi Pemasaran merasa topik-topik di atas sudah cukup sehingga tidak perlu ada penambahan topik. Sementara itu, 112 mahasiswa menginginkan topik tambahan, dengan 11 mahasiswa/i menginginkan topik tambahan berupa percakapan sehari-hari yang bisa diterapkan dalam kehidupan dan 101 mahasiswa/i lainnya menginginkan topik tambahan mengenai kebudayaan China, bisnis maupun broadcasting yang berhubungan dengan jurusan.

Topik-topik tersebut masih kurang sesuai karena bahan ajar bahasa Mandarin yang digunakan masih merupakan bahan ajar bahasa Mandarin yang masih bersifat umum. Yang dimaksud dengan "umum", yaitu bahan ajar yang bisa dipakai oleh pembelajar bahasa Mandarin di seluruh dunia dengan tidak membedakan negara maupun budaya pembelajar tersebut. Selain itu, dilihat dari bagian kosakata yang ada di dalam bahan ajar ini hanya ada Hanzi, pinyin, dan arti dalam bahasa Inggris. Sedangkan bagian dialog hanya terdapat Hanzi dan pinyin, tidak disertai dengan penjelasan maupun penerjemahan ke dalam bahasa Inggris. Bahan ajar ini jika digunakan oleh pembelajar pemula bahasa Mandarin di Indonesia tidak sesuai. Bagi pembelajar pemula, adanya terjemahan ke bahasa Indonesia dan bahasa Inggris akan dapat membantu mereka dalam memahami serta menguasai bahasa yang dipelajari. Akan lebih baik jika bahan ajar bahasa Mandarin yang digunakan oleh pembelajar pemula bahasa Mandarin memiliki terjemahan dalam bahasa Indonesia maupun bahasa Inggris karena bahan ajar bahasa Mandarin yang dilengkapi dengan terjemahan bahasa Inggris tidak cukup membantu pembelajar pemula Indonesia dalam mempelajari bahasa Mandarin.

Berdasarkan hasil kuesioner, dapat disimpulkan bahwa bahan ajar Hanyu Changcheng (Great Wall Chinese) volume 1 sampai 4 yang digunakan oleh mahasiswa jurusan Komunikasi Pemasaran masih tidak sesuai dengan kebutuhan dan permintaan jurusan Komunikasi Pemasaran dalam mempelajari bahasa Mandarin. Bahan ajar Hanyu Changcheng (Great Wall Chinese) volume 1 sampai 4 merupakan bahan ajar yang dibuat untuk pembelajar bahasa Mandarin secara umum dan terfokus pada komunikasi pada kehidupan sehari-hari. Hal ini membuat mahasiswa jurusan Komunikasi Pemasaran dalam mempelajari bahan ajar ini merasa kurang sesuai dengan kebutuhan mereka. Yang mereka perlukan adalah 
komunikasi yang bisa digunakan dalam bidang ilmu mereka.

Sekarang ini masih belum ada bahan ajar bahasa Mandarin yang dibuat khusus untuk mahasiswa jurusan Komunikasi Pemasaran. Oleh karena itu, pemilihan topiktopik dalam pembuatan bahan ajar bahasa Mandarin untuk Komunikasi Pemasaran harus lebih selektif agar dapat menyesuaikan sesuai kebutuhan dan tujuan pembelajaran bahasa Mandarin untuk jurusan ini.

\section{Bersifat Praktikal}

Bahan ajar bahasa Mandarin yang digunakan oleh mahasiswa/i jurusan Komunikasi Pemasaran juga harus bersifat praktikal. Ini disebabkan kebutuhan jurusan Komunikasi Pemasaran adalah bahasa Mandarin yang dipelajari oleh mahasiswa/i nya lebih fokus pada percakapan dan membaca. Melaluinya, mahasiswa/i jurusan Komunikasi Pemasaran hanya perlu bisa membaca karakter Han dan juga mampu merespons ketika berkomunikasi dalam bahasa Mandarin.

Berdasarkan hasil kuesioner, mahasiswa/i jurusan Komunikasi Pemasaran Universitas Bina Nusantara merasa cara belajar bahasa Mandarin yang efektif jika diurutkan dari jumlah terbanyak yang dipilih adalah latihan percakapan (97), melalui multimedia seperti lagu, menonton film (72), latihan soal untuk me-review pelajaran (59), belajar kosakata yang berhubungan dengan jurusan Markom (53), membuat proyek atau tugas berkelompok seperti recording, video (44), belajar berdasarkan buku teks (37), dan lainnya (11) seperti bermain games dan belajar di luar kelas.

Sedangkan dari 4 kemampuan dasar yang harus dimiliki dalam menguasai bahasa Mandarin, mahasiswa/i memilih kemampuan mendengar (72 orang) sebagai bagian yang paling mereka sukai. Kemampuan berbicara sebanyak 54 orang, kemampuan membaca 42 orang, dan kemampuan menulis hanya ada 27 orang. Dilihat dari hasil kuesioner yang ada, dapat disimpulkan bahwa mahasiswa/i jurusan Komunikasi Pemasaran senang dengan kegiatan belajar dan mengajar yang aktif dan juga lebih menyukai belajar bahasa Mandarin secara lisan, yaitu dengan mendengar dan berbicara. Oleh karena itu, pembuatan bahan ajar bahasa Mandarin untuk jurusan Komunikasi Pemasaran harus dilengkapi dengan latihanlatihan yang sesuai dengan karakteristik mahasiswa/i jurusan Komunikasi Pemasaran yang suka berbicara, aktif, kreatif, senang tampil di depan umum, dan lainlain. Latihan -seperti membuat video, presentasi, syuting film, membuat drama (role play), interview, serta beberapa permainan yang membantu mereka dalam menguasai bahasa Mandarin akan lebih menarik minat mereka dalam belajar bahasa Mandarin.

\section{Menarik}

Pembuatan bahan ajar bahasa Mandarin harus memiliki prinsip dasar dari pembuatan bahan ajar, yaitu menarik. Bahasa Mandarin bukanlah bahasa yang mudah untuk dipelajari, melainkan bahasa yang sering kali dianggap sulit oleh pembelajar bahasa Mandarin, terutama oleh orang Indonesia, karena bahasa Indonesia menggunakan alfabet sebagai bahasa tulisnya.

Untuk memotivasi seorang pembelajar bahasa Mandarin agar tertarik belajar bahasa Mandarin, tidak hanya dari cara pengajar mengajar yang menarik. Bahan ajar bahasa Mandarin yang digunakan harus mampu membuat pembelajar merasa tertarik untuk belajar. Bahan ajar adalah pegangan dasar bagi pembelajar untuk memperlajari suatu hal.

Bahan ajar bahasa Mandarin yang menarik bagi mahasiswa/i jurusan Komunikasi Pemasaran adalah bahan ajar yang tidak monoton. Isi materi dari bahan ajar sesuai dengan kebutuhan bidang yang mereka tekuni. Di samping itu juga dapat diselingi dengan pengenalan budaya Tiongkok, agar ketika mereka berhubungan dengan orang Tiongkok asli, tidak akan terjadi culture shock.

\section{SIMPULAN}

Berdasarkan hasil dan pembahasan, maka disimpulkan bahwa bahan ajar yang digunakan oleh mahasiswa/i jurusan Komunikasi Pemasaran Universitas Bina Nusantara sekarang tidak sesuai dengan kebutuhan dan permintaan dari jurusan Komunikasi Pemasaran. Sedangkan jika dilihat dari sisi mahasiswa/i, mereka merasa topik yang diberikan tidak sesuai dengan bidang dan kemampuan bahasa Mandarin mereka, sehingga bahan ajar bahasa Mandarin yang digunakan sekarang perlu ditinjau kembali.

Berdasarkan wawancara dan kuesioner yang sudah dilakukan, untuk saat ini belum ada bahan ajar bahasa Mandarin yang sesuai dan dapat memenuhi kebutuhan jurusan Komunikasi Pemasaran. Dengan demikian perlu dilakukan penulisan bahan ajar bahasa Mandarin yang dikhususkan untuk mahasiswa/i Komunikasi Pemasaran. Bahan ajar tersebut harus memegang tiga prinsip penulisan bahan ajar yaitu terfokus, bersifat praktikal, dan menarik. Tiga prinsip ini juga harus disesuaikan dengan karakteristik mahasiswa/i jurusan Komunikasi Pemasaran itu sendiri.

\section{DAFTAR PUSTAKA}

Dick, W., Carey, L., Carey, J. O. (2005). The Systematic Design of Instruction (6th ed). New Jersey: Pearson.

EconomyWatch. (2010, 13 Okt). China Economic Watch Analysis: The World's Largest Economy by 2035 ? Diakses dari http://www.economywatch.com/ economic- analysis/china.html

Hanban. (2006). 长城汉语-生存交际1 (Great Wall Chinese-Essentials in Communication1). Beijing: Beijing Language and Culture University Press.

Hanban. (2006). 长城汉语-生存交际2（Great Wall Chinese-Essentials in Communication2). Beijing: Beijing Language and Culture University Press.

Hanban. (2006). 长城汉语-生存交际3（Great Wall Chinese-Essentials in Communication3). Beijing: Beijing Language and Culture University Press.

Hanban. (2006). 长城汉语-生存交际4 (Great Wall Chinese-Essentials in Communication4). Beijing: Beijing Language and Culture University Press.

Li, Q. (2006). 对外汉语教材研究 (Penelitian Bahan Ajar Bahasa Mandarin untuk Orang Asing). Beijing: The Commercial Press.

Muslich, M. (2010). Text Book Writing. Yogyakarta: Arruzz Media. 
O'neill, R. (1982). Why Use Textbooks. ELT Journal, 36(2), 104-111.

Pannen, P \& Purwanto. (2011). Penulisan Bahan Ajar. Jakarta: Pusat antar Universitas untuk Peningkatan dan Pengembangan Aktivitas Instruksional Ditjen Dikti Dinas.

Prastowo, A. (2011). Paduan Kreatif Membuah Bahan Ajar Inovatif. Yogyakarta: Diva Press.

Qomariyah, N. (2011, 14 Feb). Kalahkan Jepang, Ekonomi China kini Terbesar Kedua di

Dunia. Diakses dari http://finance.detik.com/read/ 2011/02/14/103031/1570639/4/

Tanaga, S. (2008, 17 Feb). Pentingnya Bahasa Mandarin di Era Pasar Global. Diakses dari http://sylvietanaga. com/2008/02/17/pentingnya-bahasa-mandarin-diera-pasar-global/

Xiaobing,Z. (2012). 对外汉语教学入门(The Guidance of Teaching Chinese to Speakers of Other Languages). Guangzhou: Zhongshan Daxue Chubanshe.

Xun, L. (2010). 对外汉语教育学引论 (Pengenalan Pendidikan Bahasa Mandarin sebagai Bahasa Asing). Beijing: Beijing Language and Culture University Press. 